\title{
Analysis of the Technological Parameters of the Heat Exchanger in the Heating Pipe
}

\author{
Vladimir Knyazev ${ }^{1, *}$ and Gregory Bubnov ${ }^{1,2}$ \\ ${ }^{1}$ Moscow Institute of Physics and Technology, Higher School of Systems Engineering, 141701 Dolgoprudny, Russia \\ ${ }^{2}$ Moscow Technological Institute, 119334 Moscow, Russia
}

\begin{abstract}
The main purpose of this article is to analyze the selecting of technological parameters for the heat exchanger to improve the heat transfer and reduce the noise during operation in the heating pipe, which is used in the different systems of the planes and helicopters. In result of this study, the best technical parameters are found, considering different variations of deformation cutting heat exchanger pipes.
\end{abstract}

\section{Introduction}

Nowadays heating pipes are used in a wide range of aerospace systems, such as electronic cooling systems in aircraft, passive transmission cooling systems, gear box systems in helicopters and others [1]. Let's consider the principle of a heating pipe (thermosyfon) in a radiator based on heating pipe technology. The radiator consists of two independent circuits. Thermal energy comes from the trunk-heating pipe (processor) to the first circuit (heat exchanger pipe). Through the heat exchanger pipe, the energy is transmitted to the small amount of low-boiling liquid, located in the second circuit (sealed thermal panel). The pressure inside the thermal panel is reduced to $30-50 \mathrm{kPa}$. Therefore, lowboiling liquid begins to boil at 30-35 degrees Celsius. The resulting steam begins to rise up inside the thermal panel and condenses in the inner surface of the second circuit.

During condensation, thermal energy is transmitted to the surface of the second circuit and condensate flows downward due to gravity, after that the cycle repeats. According to that, thermal energy is transmitted from the trunk heating pipe to the surface of the panel, which respectively transmits this energy to the room. The difference between the temperatures of the heating transfer agent in the trunk heating pipe and the surface of the thermal panel is about 7-9 degrees Celsius. It depends on the various operating modes of the appliance.

The method of functional analysis and evaluation of significance functions [2] and the theory of multiparameter optimization [3] are used in this article. The article [4] describes deformation cutting technology, which was used to design the microstructure surfaces on the heat exchanger pipe.

The analysis of the criteria for the heat exchanger pipe, and the choice of the optimal alternative to increase efficiency of the pipe during the operation will be the result of this work.

\section{Deformation cutting technology for the heat exchanger pipe}

Technology of the deformational cutting was chosen a perspective method to improve the heat transfer and reduce the noise in the heating pipe systems. The main purpose of the Deformational Cutting is to get the macro pattern in the form of pin fins, cells, meshes, vgrooves on such materials as Copper, Aluminum and their alloys, steel and plastics, with the opportunity to increase the surface area after the process up to 12 times. For the analysis four different alternatives of the Deformation cutting steel pipes were chosen (Fig. 1). The main characteristics of the pipes are shown in the Table 1.

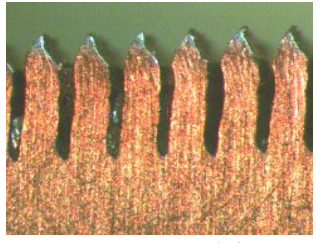

№1

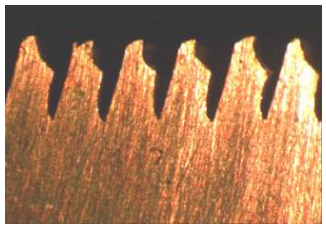

№3

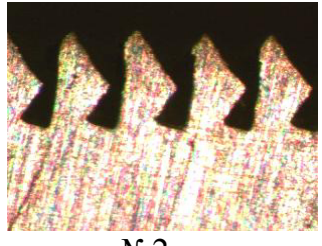

№2

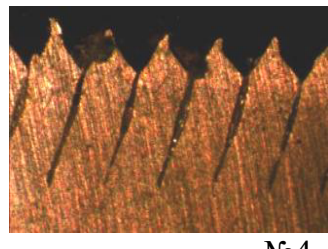

№4
Fig. 1. Types of microstructured pipes ( Type №1, №2, №3, №4). 
Table 1. Characteristics of the microstructured pipes

\begin{tabular}{|c|l|l|l|l|}
\hline Parameters /Types & №1 & №2 & №3 & №4 \\
\hline Step of the edges, mm & 0,4 & 0,5 & 0,4 & 0,4 \\
\hline $\begin{array}{c}\text { The average height of the } \\
\text { structure , mm }\end{array}$ & 0,95 & 0,75 & 0,65 & 1,15 \\
\hline $\begin{array}{c}\text { The average width of the } \\
\text { intercostal gap, } \mu \mathrm{m}\end{array}$ & 130 & $\begin{array}{l}250 / 1 \\
00\end{array}$ & 100 & 40 \\
\hline $\begin{array}{c}\text { Deviation from the vertical } \\
\text { ribs }\end{array}$ & 0 & 0 & 15 & 15 \\
\hline
\end{tabular}

\section{Functional analysis}

Functional analysis (Table 2) will help to define the most significant parameters, which could improve the heat transfer and reduce the noise in the heating pipe systems

Table 2. Functional analysis

\begin{tabular}{|c|c|c|}
\hline $\begin{array}{c}\text { Requirements } \\
\text { (Upper level) }\end{array}$ & $\begin{array}{c}\text { Requirement } \\
\text { S (Derivative) }\end{array}$ & Functions \\
\hline $\begin{array}{c}\text { Ensure the film } \\
\text { boiling }\end{array}$ & $\begin{array}{c}\text { Reduce the } \\
\text { noise }\end{array}$ & $\begin{array}{c}\text { F1 Ensure the } \\
\text { optimum width of the } \\
\text { intercostal gap }\end{array}$ \\
\hline $\begin{array}{c}\text { Increase the heat } \\
\text { transfer }\end{array}$ & $\begin{array}{c}\text { Increase heat } \\
\text { transfer of the } \\
\text { appliance }\end{array}$ & $\begin{array}{c}\text { F2 Ensure the } \\
\text { optimum height of the } \\
\text { structure }\end{array}$ \\
\cline { 3 - 3 } & $\begin{array}{c}\text { F3 Ensure the } \\
\text { optimum step the } \\
\text { edges }\end{array}$ \\
\hline $\begin{array}{c}\text { Ensure the } \\
\text { minimal changes } \\
\text { in diameter of the } \\
\text { pipe }\end{array}$ & $\begin{array}{c}\text { Increase the } \\
\text { build capacity }\end{array}$ & $\begin{array}{c}\text { F4 Ensure the } \\
\text { optimum deviation } \\
\text { from the vertical ribs }\end{array}$ \\
\hline
\end{tabular}

Use the matrix N2 (Table 3) to reduce the number of functions. The $\mathrm{N} 2$ matrix has the dimensions correspond to the number of functions. At each intersection of rows and columns the expert assessment of the pair interaction is placed. If the functions are equivalent, the sign "="is put. If the function value is stored in the line is greater than the function value stored in the column, then the sign " $>$ " is put. Otherwise, the sign " $<$ " is put.

Table 3. N2 matrix

\begin{tabular}{|c|c|c|c|c|}
\hline & F1 & F2 & F3 & F4 \\
\hline F1 & $=$ & $>$ & $=$ & $>$ \\
\hline F2 & $<$ & $=$ & $>$ & $>$ \\
\hline F3 & $=$ & $<$ & $=$ & $>$ \\
\hline F4 & $<$ & $<$ & $<$ & $=$ \\
\hline
\end{tabular}

Replace the symbols $<,=$, > with the numbers 1 , 2,3 , and sum the numeric values in each row (Table 4).
Table 4. N2 matrix (numeric values)

\begin{tabular}{|c|c|c|c|c|c|}
\hline & F1 & F2 & F3 & F4 & Total \\
\hline F1 & 2 & 3 & 2 & 3 & 10 \\
\hline F2 & 1 & 2 & 3 & 3 & 9 \\
\hline F3 & 2 & 1 & 2 & 3 & 8 \\
\hline F4 & 1 & 1 & 1 & 2 & 5 \\
\hline
\end{tabular}

Each line must be multiplied by the column vector sum in order to calculate the absolute priority function for this criterion.

Calculating the priority ranking of each function provides an estimation of the importance of this function (Table 5). By itself, this number does not make any sense and depends only on the scale of adopted assessments. Relative rating values indicate the significance of the function

Table 5. Significance of the function

\begin{tabular}{|c|c|c|}
\hline № & $\begin{array}{c}\text { Absolute value of } \\
\text { the function }\end{array}$ & $\begin{array}{c}\text { Significance of the } \\
\text { function \% }\end{array}$ \\
\hline F1 & 100 & $37,0 \%$ \\
\hline F2 & 81 & $30,0 \%$ \\
\hline F3 & 64 & $23,7 \%$ \\
\hline F4 & 25 & $9,3 \%$ \\
\hline Total & 270 & $100 \%$ \\
\hline
\end{tabular}

Implement the following notation from 0 to 1 (from worst to the best value of the parameter) (Table 6).

Table 6. Relative values of the optimization parameters

\begin{tabular}{|c|c|c|c|c|c|c|}
\hline \multicolumn{2}{|c|}{$\begin{array}{c}\text { Parameters/ } \\
\text { Alternatives }\end{array}$} & №1 & №2 & №3 & №4 & Weight \\
\hline 1 & $\begin{array}{c}\text { The average } \\
\text { width of the } \\
\text { intercostal } \\
\text { gap }\end{array}$ & 0,5 & 0,7 & 1 & 0,2 & 0,4 \\
\hline 3 & $\begin{array}{c}\text { The average } \\
\text { height of the } \\
\text { structure }\end{array}$ & 0,7 & 0,6 & 1 & 0,9 & 0,3 \\
\hline 4 & $\begin{array}{c}\text { Step of the } \\
\text { edges }\end{array}$ & 0,7 & 1 & 1 & 1 & 0,2 \\
\hline $\begin{array}{c}\text { Deviation } \\
\text { from the } \\
\text { vertical ribs }\end{array}$ & 0,5 & 0,7 & 0,7 & 1 & 0,1 \\
\hline
\end{tabular}

Germeier's method was chosen as the most suitable, among the large variety of multi-parameter optimization methods [3]. Optimization criteria were defined by the requirements to the outer surface of the heat exchanger pipe: the average width of the intercostal gap, the average height of the structure, step of the edges, and deviation from the vertical ribs. It is not feasible to sum 
the values directly to optimize the parameters of each alternative, because they have different dimensions. For that, these value parameters must be expressed in the same units. It is convenient to express them in a fraction of the best. In order to do this, the following formula is used:

$$
X=\frac{X_{b e s t}-X_{i}}{X_{b e s t} K_{i}} .
$$

Where $X$ - is the optimization value, expressed as a fraction of the better, $X_{i}$ - is the value of the parameter optimization in real terms, $X_{\text {best }}-$ is the value of the parameter optimization, the best among the considered alternatives, $K_{i}$ - is the value of the weighting factor for the $i$-th optimization parameter. The experts, depending on the particular importance of the optimization parameter, determine $K_{i}$ values.

How close the value of the integral Germeier criterion to zero, determines the optimal alternative (Table 7).

Table 7. Germeier's criteria

\begin{tabular}{|c|c|c|c|c|c|c|}
\hline \multicolumn{2}{|c|}{$\begin{array}{c}\text { Parameters/ } \\
\text { Alternatives }\end{array}$} & №1 & №2 & №3 & №4 & Weight \\
\hline 1 & $\begin{array}{c}\text { The average } \\
\text { width of the } \\
\text { intercostal gap }\end{array}$ & 1,3 & 0,8 & 0,0 & 2,3 & 0,4 \\
\hline 2 & $\begin{array}{c}\text { The average } \\
\text { height of the } \\
\text { structure }\end{array}$ & 1,0 & 1,3 & 0,0 & 0,3 & 0,3 \\
\hline 3 & $\begin{array}{c}\text { Step of the } \\
\text { edges }\end{array}$ & 1,5 & 0,0 & 0,0 & 0,0 & 0,2 \\
\hline 4 & $\begin{array}{c}\text { Deviation } \\
\text { from the } \\
\text { vertical ribs }\end{array}$ & 5,0 & 2,0 & 2,0 & 0,0 & 0,1 \\
\hline Germeier's criteria & 8,8 & 4,1 & 2,0 & 2,6 & 1 \\
\hline
\end{tabular}

\section{Conclusion}

First, deformation cutting technology for the heat exchanger pipes was described, which improves the efficiency of the heat exchange and reduces the noise during operation in the heating pipe systems. After that, multi-criteria analysis was held, to select the alternatives of the deformation cutting steel pipes through the functional analysis and multi-parameter optimization of Germeier's method. Based on this analysis, the best technical solution to increase the heat transfer efficiency and reduce the noise during operation in the heating pipe systems is the alternative №3 (Fig. 1).

\section{References}

1. D. Peter, D. Reay, Heat pipes (Elsevier, 2012)

2. B. Lightsey, Systems engineering fundamentals (Defense Acquisition Univ, 2001)

3. Y.B. Germeier, Introduction to the theory of operations research (Moscow, Nauka, 1971)

4. N.N. Zubkov, Russian Engineering Research, 35, 859-863 (2015) 